The Senate came into being officially on September 26,1949 , and the following positions were filled by election: President: Dr. Arthur Hanau; VicePresident : Prof. W. Schulze; Executive Committee : President, Vice-President and Prof. $W$. Kloth.

An area of 360 acres of the former airfield was developed for agricultural and experimental purposes during 1948, in spite of great shortages of equipment and numerous difficulties. Excellent results were obtained with all crops. Recently the Hornsen Estate, which consists of 618 acres, has been acquired for experimental purposes.

In this age, which may become known in history as the international age, marking as it does in the course of human evolution the gradual transition from rather isolated national to co-operative international endeavour, there is something significant in the setting-up of a new centre at Voelkenrode in Germany to assist co-operative research in agriculture. Agriculture has, in fact, a great role to take in providing a solid foundation for developing trust and understanding between various nations. It is our greatest industry: the fundamental basis of every country, great or small, temperate, sub-tropical or tropical. Primary and secondary industry are complementary and, in the future, as agriculture receives greater recognition and support as an essential medium for providing a balanced and flexible integration of primary and secondary industry, its importance will be greatly enhanced.

The tremendous potentialities of agriculture both as a means of supplying food to man and to animals, and as a source of raw materials for processing by secondary industry, have as yet received inadequate inquiry, support and research.

Much of the unrest, unemployment, poverty and shortages of food which have occurred since the Industrial Revolution can be traced to a grave underestimate of this basic and complementary value of agriculture. Unfortunately, it is true that much loss of valuable, or rather invaluable, top soil has occurred as a result of man's unscientific exploitation of Nature's reserves carried out under the name of agriculture; and perhaps our greatest problem of to-day and to-morrow lies in the prevention of such large-scale destruction by a world-wide development of soil conservation, and in building up soil fertility.

It is in this setting that the new centre at Voelkenrode has begun its great task. Germany has created an example of international co-operation in agriculture by arranging that the Board of Governors at this Centre shall include four representatives of agricultural science from foreign countries in addition to twelve German nominees. Voelkenrode has many well-wishers for its future success, not only in Germany but also in foreign countries.

Visitors have already been to Voelkenrode from the following countries: Australia, Denmark, Great Britain, the Netherlands, Sweden, South Africa and the United States. Dr. A. H. Boerma, European regional representative of the Food and Agriculture Organisation, visited Voelkenrode in September 1949 and met the directors of the different institutes. At a subsequent meeting of the Committee on Agricultural Technology, Dr. Boerma circulated a paper on Voelkenrode and on the activities being pursued there. The representatives of the various member governments of the Food and Agriculture Organisation present took note of the information and indicated their willingness to establish contacts with the institutes at Voelkenrode. It is of interest and indicative of the co-operative nature of the work at Voelkenrode that facilities are provided for German and foreign visitors in a well-equipped hostel possessing first-class accommodation, and it is intended that a guest house shall be opened in the near future.

It is hoped that this great venture will prove of assistance as a means of reaching a better understanding between the peoples of various nations, based on co-operative work for the benefit of all.

.T. L. SchofIELD

\section{CHEMICAL INDUSTRY OF GREAT BRITAIN}

$\mathrm{T}$ HE report on the present position of the chemical industry of Great Britain*, prepared by the Association of British Chemical Manufacturers in co-operation with the British Colour Makers' Association, the British Sulphate of Ammonia Federation, Ltd., the National Sulphuric Acid Association, Ltd., British Plastics Federation and the Superphosphate Manufacturers' Association, Ltd., is the result of an inquiry into the adequacy of the plans of the British chemical industry for the part it has to play in the national economy. The details of the expansion proposals supplied by individual firms are omitted from the report as confidential to the Board of Trade. Although therefore, from this report as published, it is scarcely possible to give a full answer to that question, the omission of such details does not affect the picture of general trends. The report is likely to be of permanent value for the comprehensive survey it gives of a most complex industry, or series of related industries, and of the factors upon which the development and efficiency of the industry depend.

The first chapter indicates the definition of the chemical industry adopted for the purpose of the survey, after discussion with the President of the Board of Trade. Heavy chemicals, industrial gases, fertilizers, dyestuffs, medicinals and other fine chemicals, explosives, plastics and other synthetic resins are included, but not the compounding of chemicals to make such products as paints, insecticides, sheep- and cattle-dips and pharmaceutical preparations. Synthetic fibres and rayon are excluded, but the chemical raw materials used in their manufacture are considered. A brief sketch of the historical background follows, with two chapters dealing successfully with such changes in the industry as are due to chemical research, the effects of plastics, the use of X-rays and biological advances, and a concise review of some achievements of the industry since the First World War. The industry's products are next described in seventeen groups, with a note on their inter-relationships. The supply of raw materials is reviewed in the following chapter, according to whether sufficient domestic supplies are available or whether supplies are drawn partly or wholly from overseas.

The most important natural resource of British industry is coal, which in the chemical industry is being used with satisfactory efficiency, although continuous study is given to new processes and powergenerating systems that may make even better use of so valuable a raw material. Proposals for a more

* Association of British Chemical Manufacturers. Report on the Chemical Industry, 1949. Pp. 76. (London: Association of British 
extended use of hydro-electric power in the electrochemical and electro-metallurgical industries, particularly in the Highlands of Scotland, have been studied with care; but it is concluded that Scottish hydro-electric power could not be used economically for chemical manufacture unless it were supplied at preferential rates. Under present conditions, in the United Kingdom sufficient tar is being produced to supply most of the raw materials needed for chemical manufacture, and the new plant being erected for the manufacture of synthetic phenol should make further imports of phenol unnecessary. Any drastic change in the method of carbonization of coal may, however, have wide repercussions on the whole chemical industry; but, since the same basic chemicals will become increasingly available from some new oilcracking plants, future prospects give no real cause for anxiety. The greatly increased interest in the chemistry of acetylene may lead to a substantial increase in the demand for carbide, but development in Britain of alternative processes for acetylene is regarded as a long-term project because of the heavy list of capital commitments to which the industry is already pledged.

Of raw materials coming partly from abroad, sulphur, pyrites and zincblende are of importance as sources of sulphur for sulphuric acid, supplying 47.4 per cent, 21.5 per cent and 8.5 per cent, respectively, of the output, spent oxide accounting for a further 16.5 per cent of the 543,305 tons required annually (as sulphur). In addition, about 100,000 tons of sulphur is required for other purposes. To reduce demands for imported sulphur, attempts are being made to devise a new way of making soluble phosphates without the use of sulphuric acid. Developments in the cracking of petroleum to yield relatively cheap reactive hydrocarbons are likely to have a great influence on the organic chemical industry as a whole, and particularly in the field of synthetic plastics and resins, and several large companies are embarking on special cracking processes to give high proportions of such hydrocarbons.

A chapter on research, development and technical service points out that in no industry is the importance of research and development so well appreciated. The chemical industry has little interest in the hardand-fast line which some have attempted to draw between pure and applied research. Research, in the industry, has three objects : the discovery of new chemicals or new physical forms of old ones likely to be of use to the industry or the general public ; the discovery of the most efficient means of producing chemicals and their translation to manufacture ; and the discovery of the most efficient means of using these chemicals. The importance of technical service in both the export trade and the home market is stressed, and also the encouragement given by the industry to scientific publication. There is no evidence of any considerable overlap in research beyond that which is desirable; but while the industry gives generous support to fundamental research in the universities, it does not lend itself to the arrangement of a comprehensive research association. It is estimated that the industry employs on research and development 10,100 persons, including 3,000 professionally qualified scientific workers, and that the annual expenditure of $£ 8,500,000$ will rise to $£ 11,400,000$ when expansion schemes, which now number more than two hundred, are completed. Of the $£ 8,300,000$ of additional capital expenditure involved, $£ 1,560,000$ has already been spent.
In the following chapter, on process development and plant, reference is made to research on unit processes and to the need for giving every possible encouragement to British instrument makers in their efforts to produce designs comparing favourably with those from other countries. A chart giving the cost indexes for the construction of chemical plants shows that the cost of replacing plant constructed before the War is to-day almost two and a half times the original cost. This point is again stressed in the next chapter, on patents and monopoly, as one of three reasons why economic monopolies are an essential feature of efficient operation of the industry. The report emphasizes that there are often alternative materials available to users, and that monopoly in a chemical product does not necessarily mean absence of competition. A second factor is the lively sense of manufacturers of the dangers attached to a monopoly that may attract not only criticism but also the envious eyes of a competitor. It is recognized that price agreements can give rise to dangers through groups of manufacturers being less sensitive than the individual manufacturer to either criticism or competition; and the report welcomes the Monopolies and Restrictive Practices Act not only because it will protect the public against any undesirable restrictive practices by the industry, but also the industry itself against misinformed or ill-considered criticism for maintaining just those monopolies that are an essential feature of efficiency and productivity.

The location of factories, and staff and labour relations, are discussed in the next two chapters, in which the total number of employees is given as 116,569 men and 25,248 women. The scientific staff numbers 6,176 with 33,581 other administrative, technical, clerical and sales employees, of whom 12,671 are women. Works councils exist for 89 per cent of the labour in the industry, joint production committees for 78 per cent, education schemes for 90 per cent, training schemes for 79 per cent, superannuation schemes for 73 per cent, medical schemes for 86 per cent and safety schemes for 91 per cent. As evidence that the productivity of the industry is increasing, the report cites the rise in the industry's prices of only 56 per cent during the decade 1938-48, and an increase of less than half this in the price of one of its most important products, in comparison. with a general rise of 124 per cent in wholesale prices. A review of future trends and expansion, from which details confidential to the Board of Trade are omitted, indicates that fruition of all the schemes, representing a total expenditure of some $£ 200$ millions and an increase of 25,000 in employees, will increase the potential annual productivity capacity of the industry by 70 per cent in terms of value. The most serious difficulty in the completion and operation of these new schemes appears to be the present scarcity of scientific and technically trained staff. Replies to a questionnaire from the Association of British Chemical Manufacturers to its members in the autumn of 1948 suggested that a 40 per cent increase in the total of 6,000 chemists then employed by the industry was likely to be required by 1953. Physicists, pharmacologists, biologists, microbiologists and mathematicians are also required, and it seems probable that. for many years to come the industry could absorb more than its share of the scientific workers and technologists that the teaching institutions of Britain can supply.

Discussing in conclusion the future of the industry, the report directs attention to the marked increase 
in the ratio both of new capital and of new production capacity to man-power represented by the new schemes, and estimates that in 1951 the output of the industry should be 50 per cent greater than in 1946. On completion of the expansion schemes, a reduction of imports by $£ 28$ millions is forecast by the manufacturers; but this is regarded as too high, as is the estimate of a $£ 49$ millions increase in exports (including plastics). Nevertheless, on the assumption that the plans of the industry for rehabilitation and expansion are accomplished promptly, and subject to certain reservations about sulphuric acid, it is believed that, so far as can be foreseen, the industry will prove able to meet not only the full needs of the home market, but also to eliminate avoidable chemical imports and provide a large increase in exports. It is unlikely that the expenditure on research is exceeded in any other industry in Great Britain, and the figure compares well with corresponding figures in other countries, such as the United States. The report maintains that there is evidence that the industry has within itself the resources, vigour and foresight to meet the foreseeable future and also to maintain its position in the longer term. In conclusion, it is urged that in this immensely complicated industry or series of indus. tries, which is so often a continuous adventure into the unknown, the national interest will best be served by the utmost freedom of enterprise.

\section{ORIGIN OF THE FLUCTUATIONS IN THE INTENSITY OF RADIO WAVES FROM GALACTIC SOURCES}

\section{Cambridge Observations}

$\mathrm{T}$ HE discovery by Hey, Parsons and Phillips ${ }^{1}$ of a variable component of the radio emission from the constellation of Cygnus suggested that at least part of the galactic radiation was due to discrete sources of small angular diameter. Later observations by Bolton and Stanley ${ }^{2}$ and by Ryle and Smith ${ }^{3}$ showed that the source subtended an angle of less than 8 minutes of arc. Ryle ${ }^{4}$ has summarized the evidence concerning the nature of the sources, and has shown that if the observed fluctuations are due to variations of the emission from the source, and are not the result of some diffraction mechanism in the earth's atmosphere, it is possible to deduce the maximum physical dimensions of the source from the observed period of the fluctuations. It is therefore of importance to determine whether the observed fluctuations are caused by some relatively local diffraction mechanism, or whether they represent genuine variations of the emission from the source.

In a private communication, Dr. J. L. Pawsey has described some experiments by Bolton, in which tbe source in Cygnus was observed simultaneously from sites in Australia and New Zealand. The records of fluctuations obtained in these experiments were markedly different at the two sites, and therefore suggested a comparatively local origin. In these experiments, however, the observations were made when the angle of elevation of the source was small; the radiation was therefore incident on the ionosphere

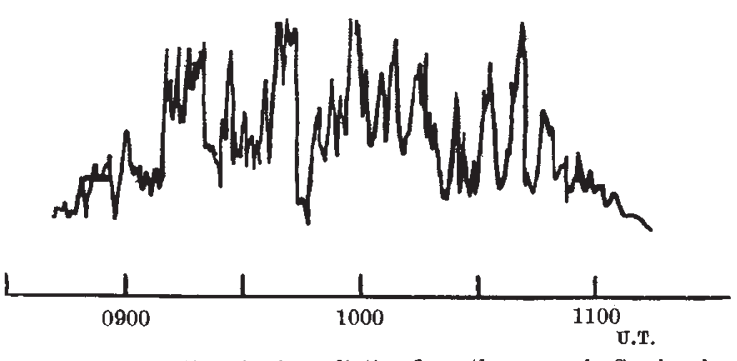

Fig. 1. Fluctuations in the radiation from the source in Cassiopeia on a wave-length of $6.7 \mathrm{~m}$.; October 27,1949

and troposphere at a rather large angle. Since it was possible that the refraction effects in those experiments might cause fluctuations sufficiently large to mask any genuine variations of the incident radiation, it was decided to repeat the experiment using an observing technique which permitted observation of the source with a relatively much smaller angle of incidence $\left(12^{\circ}\right)$, for which the refraction effects should be greatly reduced. It was also possible to make similar observations of the other intense source in the constellation of Cassiopeia, which had been found in previous experiments to be relatively less disturbed.

Two series of experiments have therefore been carried out; the first of these was done in conjunction with Little and Lovell, and involved simultaneous observations on a wave-length of $3.7 \mathrm{~m}$., using receivers at Cambridge and Jodrell Bank, Cheshire (separation $210 \mathrm{~km}$.). A detailed account of these observations is given in the following communication from Little and Lovell; but no detailed correlation between the rapid fluctuations of intensity at the two receivers was found.

The second series of observations was made by the Cambridge workers on a wave-length of $6.7 \mathrm{~m}$., using spacings of up to $170 \mathrm{~km}$. In these observations two types of fluctuations were found.

(1) On many nights, rapid fluctuations similar to those on a wave-length of $3 \cdot 7 \mathrm{~m}$. were observed; no detailed correlation was found when the receivers were separated by more than $20 \mathrm{~km}$. A typical record of this type of fluctuation is shown in Fig. 1. Observations on both $3.7 \mathrm{~m}$. and $6.7 \mathrm{~m}$. have shown that this type of fluctuation involves variations of the intensity both above and below the mean value. This observation suggests strongly that diffraction, such as might be caused in the ionosphere, is responsible for the disturbances, although there are two difficulties in such an explanation. First, it has been found that simultaneous observations at Cambridge on $3.7 \mathrm{~m}$. and $6.7 \mathrm{~m}$. often show considerable cor-

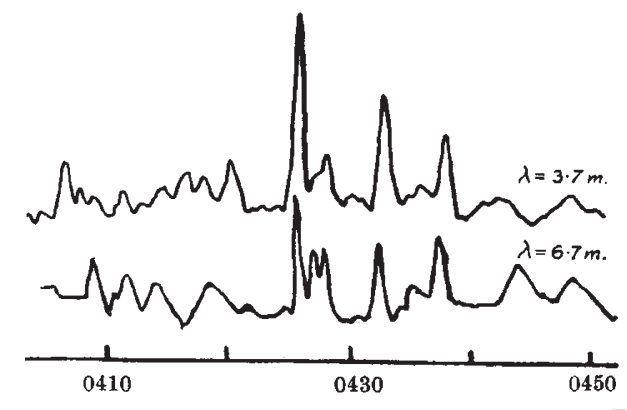

U.T.

Fig. 2. Fluctuations in the radiation from the source in Cassiopeia, showing correlation between wave-lengths of $3.7 \mathrm{~m}$. and $6 \cdot 7 \mathrm{~m}$. 